\title{
SOME RECENT DATA ON THE USE OF DRUGS IN EUROPE AND ROMANIA AMONG YOUNG ADULTS AND STUDENTS, REGARDING ADMISSIONS TO TREATMENT AND EMERGENCIES ASSOCIATED WITH THE USE OF DRUGS. SOME TENDENCIES AND CORRELATIONS
}

Corina Demian, CPECA Cluj

\begin{abstract}
In Europe, the European Monitoring Centre for Drugs and Drug Addiction (EMCDDA) collects data in the field in order to offer a general perspective on the issue. Objective and comparable information regarding drugs, addictions and their consequences is offered and independent scientific analyses can be run to support the decisions made at European and national levels. In order to do so, EMCDDA relies on a network of national centres. The data are then transcribed in the European Report on drugs, and other documents. The data on the use of tobacco, alcohol and other drugs by youths are also collected within the ESPAD project or other studies. Among the many existing data, the article selects a few regarding the prevalence of the use of drugs in Europe and in Romania (the prevalence of lifelong use, use in the past year and in the past month). A few recent data are presented on the use of cannabis (the most commonly-used drug in Europe, with an increasingly high level of THC), on the use of new psycho-active substances, tobacco and alcohol, and other potentially addictive activities. We also present data on the admissions to treatment and emergencies associated with use, during 20172019. Finally, we mention a few tendencies and correlations resulted from the studies: the early onset of the smoker, friends who use, the perception that most friends use, certain parental styles and a low social
\end{abstract}

economic statute - these are all significant predictors for the use of tobacco, alcohol or other drugs.

Key words: drugs, prevalence, treatment, emergencies, correlations

\section{Introduction}

In order to gain a general perspective on how the drug situation is evolving, in Europe, collecting data on drugs, drug addictions and their consequences is mainly done by the European Monitoring Centre for Drugs and Drug Addiction (EMCDDA). By using a multidisciplinary approach, the EMCDDA provides objective, trustworthy and comparable information on drugs, drug addiction and consequences by helping increase awareness of their impact on people and on society. The aim of this centre is to provide proof and independent scientific analyses, seeking to support decisions made at European and national level; to contribute to protecting the citizens of Europe against the continuous threats of drugs on individuals and society. In order to collect and analyse data according to the joint data collection standards and tools, the EMCDDA coordinates and is based on a network of approx. 30 national monitoring centres (the REITOX network), while also collaborating with European and international institutions/ bodies, and with non-Member States.

* Author correspondent: Corina Demian, CPECA Cluj, e-mail:

Article received: 23.11 .2021 , accepted: 29.11 .2021 , published: 15.12 .2021

Cite: Demian C. Some recent data on the use of drugs in Europe and Romania among young adults and students,regarding admissions to treatment and emergencies associated with the use of drugs. Some tendencies and correlations. The Journal of School and University Medicine. 2021;VIII(4):34-39 
The results of data monitoring at a national level are transmitted to the Centre for analysis and are then published in the European Drug Report, in annual national reports, in the Statistics Bulletin and other documents and publications [1]. Aside from the data collected by the EMCDDA, data on the use of tobacco, alcohol and other drugs among youth are also collected as part of European projects. One of the latter is the ESPAD project (European School Survey Project on Alcohol and Other Drugs) - a study carried on in schools, concerning the use of tobacco, alcohol and illicit drugs (among students aged 16), carried through every 4 years, in 28 countries [2]. The data on addiction with or without substances are collected and analysed within several studies and research, by experts from various fields, as addictions are becoming an increasingly worrying topic, in the way they can affect people's lives on many levels.

\section{Some data on the prevalence of the use of drugs (any type of illicit drug)}

One of the monitored indicators, aside from the lifelong prevalence (at least one-time use) and the prevalence in the past 30 day, is also the prevalence of the use of drugs within the past 12 months. This is an indicator of the recent use of drugs and it is the most common among young adults, according to the EMCDDA's most recent report (The European Drug Report 2021: Trends and Developments, containing data from 2019), with approx. 19,1 mill. young adults (15-34 years old) who have used drugs in the past year $(16 \%)$. Among the youths who have used drugs in the past year, the men-women ratio is two to one [3]. The most often used drug is cannabis, with a use prevalence of approx. 5 times higher than that of other drugs, and the increasingly high content of THC (tetrahydrocannabinol) causing health concerns (the cannabis resin and plant sold across Europe has approx. twice as much THC, on average, than it did a decade ago) [4]. In the 2019 annual report, the rate of use prevalence in the past year among young adults varied between 3,5\% in Hungary and 21,8\% in France. Beginning with the year 2000, several countries have known increasing trends in the prevalence of cannabis use in the past year, among young adults. Among these countries, Ireland and Finland presented the most recent data indicating levels close to the EU average of $14,4 \%$; Bulgaria and Romania, too, although with lower level [5]. The same is valid for those admitted to treatment; within the 24 countries that present the data, the total number of people admitted to treatment for the first time for problems associated to the use of cannabis has increased by $45 \%$ between 2009 and 2019 [3]. In Romania, among the general population, there is an $11,9 \%$ lifelong prevalence for the use of any kind of illicit drug (10,7\% if we exclude the use of over-the-counter drugs). In the past year, the prevalence of this type of use is $6,7 \%$, while for the use in the past month the prevalence is $4,2 \%(6 \%$, and 3,9\% without medicine) [4]. Considering the age groups, the greatest prevalence in the use of drugs, in general (any type of illicit drug), is among young adults (15-34 years old), with $16,9 \%$ of them using at least once in their lifetime (experimental use), $10 \%$ of them have used drugs in the past 12 months (recent use), and $6,6 \%$ of them have used within the past 30 days (current use) $[6,7]$.

\section{Data on the prevalence of the use of cannabis}

According to the ESPAD study conducted among the general population, in 2019, on the use of cannabis, in Romania, among the general population (15-64 years old) there is a lifelong prevalence of $6,1 \%$, a $3,5 \%$ prevalence of the use of cannabis within the past year, and a $1,8 \%$ prevalence of use within the past month. If we refer to the daily or almost daily use, $0,31 \%$ of those included in the study declared to use daily or almost daily with ages between $15-34$ years old (young adults), 0,59\% declared to use daily or almost daily [8]. On a national level, for the use of cannabis among pupils, more specifically 16 year-olds (according to the most recent data of the ESPAS study - 2019), 8,7\% of teenagers of 16 years old declared the experimental use of cannabis $(16 \%$ the European average), 7,2\% have used within the past year (12,9\% the European average), and $3,3 \%$ of them have smoked marijuana or hash in the past month $(7,4 \%$ the European average). The prevalence of the use of cannabis continues to grow among boys [7]. 


\section{Data on the prevalence of the use of new psychoactive substances (NPS)}

A category of drugs that cause growing concern are the new psychoactive substances (NPS) or so-called ethnobotanicals (mainly synthetic cannabinoids, synthetic cathinones and synthetic opioids) [7], albeit the inquiries among the general population (where such inquiries are available) suggest a low level of use of new psychoactive substances in the European countries [11]. Nonetheless, synthetic cannabinoids and other new psychoactive substances have already been proved to cause potential damage to health with the existence of naturally modified cannabis products with synthetic very strong cannabinoids, as well as the deaths reported in 2020 associated with the use of such substances [3]. In Romania, $6,3 \%$ of the general population aged between 15 and 64 included in the General Population Study have experimented the use of NPS; $3,1 \%$ of the interviewees declared to have used NPS in the past year, and 2,5\% mentioned using in the past month. According to the ESPAD 2019, 3,2\% of students aged 16 included in the study declared NPS experimental use, and 2,2\% mentioned recent use [7].

\section{Other data}

The ESPAD collected and analysed data on 16 year-old students in Europe, including data on the use of tobacco and alcohol, the use of nonmedical medicine and gambling, and playing games on social media. Between 1995 and 2019, the average for the experimental use of tobacco decreased from $68 \%$ to $42 \%$; in the case of use during the past month, it decreased from $33 \%$ to $20 \%$, and in the case of daily use it decreased from $20 \%$ to $10 \%$. The use of alcohol remains high among teenagers in Europe, with an average of over three quarters (79\%) among students who have consumed alcohol at least once in their lifetime, and almost half (47\%) among those who have consumed alcohol in the past month ("current use"). The data regarding the trends, however, show a constant drop; for instance, in 2003, 91\% of those included in the study reported use of alcohol at least once in their life, and $63 \%$ reported use during the past month. $6,6 \%$ of those in question reported having consumed tranquilisers or sedatives at least once in their life, and $4 \%$ reported having used painkillers to "change their mood" [12]. Gambling for money had become a popular activity among students in Europe, $22 \%$ of the respondents having reported gambling - at least for one game - in the past 12 months (especially the lottery). It is estimated that a 7,9\% of students have placed financial bets online, during the same period of time. 5\% of students who have placed bets in the past 12 months entered the category of problem gambling [10]. Approx. $60 \%$ of the respondents reported to have played digital games in the past month, on a typical school day (69\% on a free day). Approx. $94 \%$ of the respondents reported to have used social networks in the past week. On average, the users spent 2-3 hours on social networks on a regular school day, and the rate increased to 6 or more hours on free days [12].

\section{Data on admissions to treatment and showing up in emergency rooms}

When it comes to getting treatment for the use of drugs, in Europe, most of it is outpatient treatment, as specialised centres of treatment are the greatest supplier for this kind of services (in number of treated consumers). In 2017, almost half (54\%) of those admitted to specialised treatment for the use of drugs, in Europe, addressed those services on their own will (including on recommendation by family or friends) [5]. Between 2017 and 2019, an average of 440000 admissions to treatment were registered every year, for any type of drug used. In 2019, approx. 111000 people around Europe started getting specialised treatment for the use of drugs due to problems associated to the use of cannabis (35\% of the total demands for admission to treatment) [3]. In Romania, 3577 addicted people were admitted to treatment in 2017, 4266 in 2018, and 4283 in 2019. Most applications for treatment were addressed due to the use of cannabis and this type of demands were the highest among the total number of beneficiaries. Also in 2019 , over three quarters of the total number of people who sought treatment for the use of drugs addressed treatment centres on their own initiative, including upon recommendation from family/friends (approx. a quarter), or have been referred to research bodies (approx. half). In 2019, the subpopulation of consumers of new psychoactive substances (NPS) admitted 
to treatment mainly included males $(88,7 \%)$ aged 24,6 on average, almost half of them with a low level of education, and almost a quarter of them being pupils or students $(22,8 \%) .6,5 \%$ of the beneficiaries of assistance services for the use of drugs were people under 18. Of these, over half declared having used cannabis $(56,3 \%)$, while a third sought help due to the problems caused by NPS use [7].

In the case of those who have sought help in the emergency rooms for acute intoxication associated with the use of drugs - these were monitored by the European Drug Emergencies Network (EuroDEN Plus) that includes 27 hospitals (sentinels) around 19 European countries. Although these case reflect the general context within those countries, they nonetheless offer a perspective on the trends regarding drug-related emergency presentations, and there is a general tendency of increase in the number of cases within these hospitals, approx. $3 / 4$ of people being men. In Europe, in 2017, cocaine was the most frequently used drug that cause emergency presentations; on second place, there was heroin and cannabis; in 2018, the most frequently used drug that caused emergency presentations was cannabis, followed by cocaine and heroin [3]. In Romania, between 20172019, there were around 3000-5000 medical emergencies due to the exclusive use of illicit drugs. In 2019 , of the total number of emergencies, almost one third $(30,1 \%)$ were declared to be as a result of use of new psychoactive substances (alone or combined); in $22,3 \%$ of the cases, there was use of cannabis, and in $11,9 \%$ of the total number of cases - the use of opioids. Between 2012-2019, there was an increasing trend in emergencies due to the use of NPS and cannabis, and a decreasing tendency in emergencies caused by use of medicine [7].

\section{Some tendencies and associations}

A study based on ESPAD, published in 2018, sought to investigate the tendencies of tobacco, alcohol and cannabis use between 1999 and 2015 (daily use of cigarettes, weekly use of alcohol, intense monthly episodic use of alcohol and monthly use of cannabis) in teenagers around Europe, based on regions. The results showed that 16-year-old students tended to greatly reduce the use of cigarettes and to moderately decrease the use of alcohol, despite regional differences in the prevalence. Regarding the use of cannabis, the trends were increasing especially in Southern Europe and in the Balkans [13]. The various studies, including those run on twins $[14,15,16]$, sought to identify the existing correlations between the use of drugs and various individual factors, family-related or social economic. A longitudinal study conducted in Finland, on twins, found that the following were significant predictors for the use of cannabis and other illicit drugs: early onset of smoking, drinking to intoxication, the existence of equal peers (colleagues or friends) who had experience in smoking and use of drugs, weekly alcohol consumption and inebriation of the father and his aggressive behaviour. Among these factors, the strongest predictor was the early onset of smoking [15]. Other research, too, focused on the consumption of alcohol in adolescence, reached the conclusion that drinking or smoking among friends is an important predictor [16]. It seems that during this stage of growth, it is often the availability and choice of certain friends who use drugs to contribute to the ever more harmful use of drugs, over the years [17]. When drawing a comparison between girls and boys, having friends who drink, smoke or use drugs or who get involved in delinquent behaviours is more predictive in the case of girls, than it is for boys [16]. In the case of 16-year-olds, there were important correlation between smoking and the great number of friends who smoke, but also between smoking and going out most evenings. The use of cannabis and illicit drugs was strongly tied to having friends or older siblings using these substances. Another important correlation exists between the use of substances and the absence of rules/social chaos [18]. A recent research published in 2021 also concluded that the most important predictive factor for the risky use of psychoactive substances was the perception that most/all friends were involved in such behaviour. Moreover, the lack of support from parents, the minor personal adhesion to rules and low school performance were also significant in using [19].

Studies which considered the parenting style and the children's use of psychoactive substances showed that the styles of parenting influenced the behaviour in the use of psychoactive substances [20]. A very popular classification of these styles is done 
on four categories, based on two dimensions, support and control: the democratic-authoritarian style - involving availability to offer affection and reply to the child's needs and emotions (affection, care, support), while setting boundaries and rules (without blocking autonomy with unjustified restrictions); the dictatorial style - not responding to the child's needs and emotions, setting rules and excessive control; the permissive style - insuring affection and responding to child's needs, but not setting a structure, rules, or monitoring the child; the uninvolved style - neglecting, not replying to the child's needs, not monitoring them or setting boundaries. Some research conclude that the democratic-authoritarian style is best correlated to the decreased frequency in drinking among teenagers, while the neglecting type is associated with an increased frequency in using [21]. Other studies, which consider the interventions over parents, looked for their efficiency in preventing or reducing the use of substances among teenagers, concluding that setting rules, monitoring and communication between parent and child led to positive results [22]. Others showcased the relationship between the permissive parental style and the neglecting one on the one side, and the use of alcohol among teenagers and young adults, on the other side [20]. There are, however, studies supporting that even a permissive parental style could give similar results as the democratic-authoritarian one [23].

Another research based on the data taken from the Health Behaviour in School-aged Children study (HBSC) - Behaviours related to the well-being of pupils 2005/2006, conducted by the World Health Organisation, within 35 countries, sought the influence of social economic factors over smoking, considering also the psycho-social aspects such as family structure, relationship to parents or school performance. The conclusions were that parents with a lower social economic statute have less material and psychological resources, which may have negative effects on the quality of the marital relationship and on that between parent and child. Teenagers in monoparental families or who have difficult relationships with their parents may consider smoking a way of dealing with this inappropriate family environment [24]. The low social economic statute cannot be neglected when considering the risk of consumption of psychoactive substances by teenagers and youth. Unfortunately, an increasing diversity of people are affected by drugs and addictions both personally, family-related, professionally, socially and even at the level of the community; in order to reduce this condition, we ought to apply strategies that have proved to be efficient.

\section{Bibliography}

1. https://www.emcdda.europa.eu/about_en

2. http://www.espad.org/reports-documents

3. The European Monitoring Centre for Drugs and Drug Addiction (2021), the 2021 European Drug Report: Trends and Developments, the Publication Office of the European Union, Luxemburg, 8,12-16

4. https://www.emcdda.europa.eu/system/files/attachments/13242/HighlightsEDR2020_RO_Final_web1.pdf

5. The European Monitoring Centre for Drugs and Drug Addiction (2019), the 2019 European Drug Report: Trends and Developments, the Publication Office of the European Union, Luxemburg, 44

6. https://www.emcdda.europa.eu/data/stats2021/gps_en

7. The National Anti-drug Agency, the Romanian Monitoring Centre for Drugs and Drug (2020) National Drugs Report 2020 Romania: New Developments and Tendencies (30, $35,24,66,70,105-107,142,147)$

2019.pdf

8. http://ana.gov.ro/wp-content/uploads/2020/09/GPS-

9. http://ana.gov.ro/wp-content/uploads/2020/11/ ESPAD-2019_3.pdf The 2019 study in schools regarding the use of tobacco, alcohol and illicit drugs in Romania

10. ESPAD Group (2020), ESPAD Report 2019: Results from the European School Survey Project on Alcohol and Other Drugs, EMCDDA Joint Publications, Publications Office of the European Union, Luxembourg www.emcdda.europa.eu/ publications/joint-publications/espad-report-2019_en

11. The European Monitoring Centre for Drugs and Drug Addiction (2020), the 2020 European Drug Report: Important Aspects, the Publication Office of the European Union, Luxemburg, 24

12. https://www.emcdda.europa.eu/news/2020/9/ highlights-espad-2019_en

13. Kraus L, Seitz NN, Piontek D, Molinaro S, Siciliano V, Guttormsson U, Arpa S, Monshouwer K, Leifman H, Vicente J, Griffiths P, Clancy L, Feijão F, Florescu S, Lambrecht P, Nociar A, Raitasalo K, Spilka S, Vyshinskiy K, Hibell B. (2018) 'Are The Times A-Changin'? Trends in adolescent substance use in Europe. Addiction. Jul;113(7):1317-1332.

14. Huizink AC, Levälahti E, Korhonen T, Dick DM, Pulkkinen L, Rose RJ, Kaprio J. (2010) Tobacco, cannabis, and other illicit drug use among Finnish adolescent twins: causal relationship or correlated liabilities? J Stud Alcohol Drugs. 71(1):5-14

15. Korhonen T, Huizink A, Dick DM, Pulkkinen L, Rose RJ, \& Kaprio J (2008). Role of individual, peer and family factors in the use of cannabis and other illicit drugs: A longitudinal 
analysis among Finnish adolescent twins. Drug and Alcohol Dependence. 97:33-43.

16. Rose, RJ, Salvatore JE, Aaltonen S, Barr PB, Bogl LH, Byers, HA, Heikkilä K, Korhonen T, Latvala A, Palviainen T, Ranjit A, Whipp A. M., Pulkkinen L, Dick DM, \& Kaprio J (2019). FinnTwin 12 Cohort: An Updated Review. Twin research and human genetics: the official journal of the International Society for Twin Studies, 22(5):302-311.

17. Otten, R., Mun, CJ, \& Dishion, TJ (2017). The social exigencies of the gateway progression to the use of illicit drugs from adolescence into adulthood. Addictive behaviors, 73:144-150.

18. Kokkevi A, Richardson C, Florescu S, Kuzman M, Stergar E. (2007) Psychosocial correlates of substance use in adolescence: a cross-national study in six European countries. Drug Alcohol Depend. 5;86(1):67-74.

19. Helmer SM, Burkhart G, Matias J, Buck C, Engling Cardoso F, Vicente J. (2021) "Tell Me How Much Your Friends Consume"-Personal, Behavioral, Social, and Attitudinal Factors Associated with Alcohol and Cannabis Use among European School Students. Int J Environ Res Public Health. 10;18(4):1684.
20. Choudhury N, Roy S (2021) The effect of parenting styles on personality: a review of literature. Int J Adv Res. 9: 56-60.

21. Berge J, Sundell K, Öjehagen A, Håkansson A. (2016). Role of parenting styles in adolescent substance use: results from a Swedish longitudinal cohort study. BMJ open, 6(1)

22. Kuntsche S, Kuntsche E (2016) Parent-based interventions for preventing or reducing adolescent substance use - A systematic literature review. Clin Psychol Rev. 45:89-101.

23. Calafat A, García F, Juan M, Becoña E, FernándezHermida JR. (2014) Which parenting style is more protective against adolescent substance use? Evidence within the European context. Drug Alcohol Depend. 1;138:185-92.

24. Moor I, Rathmann K, Lenzi M, Pförtner TK, Nagelhout G, de Looze M, Bendtsen P, Willemsen M, Kannas L, Kunst A, Richter M, (2015) Socioeconomic inequalities in adolescent smoking across 35 countries: a multilevel analysis of the role of family, school and peers, European Journal of Public Health. 25(3):457-463 